\title{
Atlantic Ocean influence on a shift in European climate in the 1990s
}

Article

Accepted Version

Sutton, R. and Dong, B. (2012) Atlantic Ocean influence on a shift in European climate in the 1990s. Nature Geoscience, 5. pp. 788-792. ISSN 1752-0908 doi:

https://doi.org/10.1038/ngeo1595 Available at https://centaur.reading.ac.uk/30109/

It is advisable to refer to the publisher's version if you intend to cite from the work. See Guidance on citing.

Published version at: http://www.nature.com/ngeo/journal/v5/n11/full/ngeo1595.html

To link to this article DOI: http://dx.doi.org/10.1038/ngeo1595

Publisher: Nature Publishing

All outputs in CentAUR are protected by Intellectual Property Rights law, including copyright law. Copyright and IPR is retained by the creators or other copyright holders. Terms and conditions for use of this material are defined in the End User Agreement.

\section{www.reading.ac.uk/centaur}

\section{CentAUR}

Central Archive at the University of Reading

Reading's research outputs online 


\title{
Atlantic Ocean influence on a shift in European climate in the 1990s
}

\author{
Rowan T. Sutton and Buwen Dong
}

National Centre for Atmospheric Science, Department of Meteorology, University of Reading

European climate exhibits variability on a wide range of timescales. Understanding the nature and drivers of this variability is an essential step in developing robust climate predictions and risk assessments. Previous research has suggested that the Atlantic Ocean may be an important driver of variability in European climate on decadal timescales ${ }^{1-6}$, but the importance of this influence in recent decades has been unclear, partly because of difficulties in separating the Atlantic Ocean's influence from other influences such as the tropical Pacific Ocean and the stratosphere ${ }^{7-12}$. Here we show that, during the 1990s, there was a substantial shift in European climate towards a pattern characterised by anomalously mild, wet, summers in northern Europe, and hot, dry, summers in Southern Europe, with related shifts in spring and autumn. These changes in climate coincided with a major warming of the North Atlantic Ocean $^{13}$, towards a state last seen in the 1950s. The patterns of change in the 1990s are consistent with previous changes that have been attributed to the North Atlantic Ocean ${ }^{4,6}$, and provide compelling evidence that the Atlantic Ocean was the key driver. Our results suggest that the recent pattern of anomalies in European climate will persist as long as the North Atlantic Ocean remains anomalously warm.

The observed pattern of multidecadal variation in North Atlantic sea surface temperatures (SST) has become known as the Atlantic Multidecadal Oscillation or $\mathrm{AMO}^{14,4,5}$ (Fig 1). The instrumental record shows that, relative to the average temperature of the rest of the world's oceans, the temperature of the North Atlantic Ocean has fluctuated between anomalously warm and anomalously cool phases, each lasting several decades at a time. Palaeoclimate records suggest that similar variations extend much further back in time ${ }^{3,15}$. In climate model simulations AMO-like variations in SST are closely related to variations in the Atlantic Meridional Overturning Circulation $(\mathrm{AMOC})^{3,5}$. These variations can arise in the absence of any external forcings ${ }^{5}$, but can also be influenced by such forcings ${ }^{16,17}$. The extent to which recent variations in the AMO have been influenced by external forcings is a subject of active research ${ }^{16,17}$. Here, however, we focus on the impacts of the AMO rather than its drivers.

Climate models suggest that variations in the AMO can cause significant climate impacts in many regions, including North Africa, North and South America, South and East Asia and Europe ${ }^{1-6,18-21}$. For Europe, Sutton and Hodson ${ }^{4}$ (hereafter SH05) showed that the warm state of the North Atlantic Ocean in the period 193160 , relative to the period 1961-90, forced anomalous low pressure and increased precipitation over western Europe in summer. Knight et $\mathrm{al}^{5}$ (hereafter KFS06) analysed AMO variability in a long climate model control run and showed summer impacts on sea level pressure and precipitation that were very consistent with the findings of SH05. They also found impacts on European climate in other seasons. In addition, KFSO6 showed evidence of a significant correlation in observations between the AMO index and the Central England Temperature index in summer and autumn. Subsequently, Folland et al $^{6}$ showed that the AMO in observations is also correlated on decadal timescales with an index of atmospheric circulation which they termed the Summer North Atlantic Oscillation (NAO).

During the 1990s the North Atlantic returned to a warm state similar to the warm state of 1931-60 (Fig 1). Recent evidence suggests that this 1990s warming was largely caused by an acceleration of the AMOC, and 
associated northward ocean heat transport, in response to the persistent positive phase of the winter NAO in the 1980s and early $1990 \mathrm{~s}^{13,22}$. Since the 1990s the warm conditions have persisted. The pattern of North Atlantic SST anomalies for the recent warm period (1996-2010) is very similar to that for the previous warm period (1931-60), albeit that the magnitude of the (detrended) anomalies is slightly greater in some regions (Fig $1 \mathrm{c}$,d). Outside the North Atlantic there is also some consistency between the two periods, but the anomalies are generally weaker and noisier. (Note that any similarity outside the North Atlantic between the two periods is greatly diminished if no detrending is used - see Fig S5 and SI.) The similarity between the two periods in the pattern of North Atlantic SST anomalies suggests that similar mechanisms may have been responsible for the transitions, and that similar climate impacts may have been excited. To assess the climate impacts we examine the anomalous patterns of surface air temperature, precipitation, and sea level pressure for the two warm periods, relative to the intervening cool period ( 1964-93). Because it is particularly difficult to separate in winter the ocean's influence on the atmosphere from the atmosphere's influence on the ocean ${ }^{23}$, we focus on spring, summer and autumn. To focus on the role of the North Atlantic Ocean we detrend the observational data using a low-pass filtered index of SST outside the North Atlantic (see Fig 1 and Methods Summary).

The patterns of surface air temperature (SAT) anomalies over Europe for the two warm periods are very similar (Fig 2). In all three seasons, warm anomalies are found, but there is seasonal variation. In spring, significant warm anomalies are limited to western Europe, with the largest anomalies $\left(>0.8^{\circ} \mathrm{C}\right)$ over continental western Europe. In summer, warm anomalies extend much further east into central and eastern Europe and the largest anomalies $\left(>1.0^{\circ} \mathrm{C}\right)$ are found in the southern regions bordering the Mediterranean Sea. In autumn, by contrast, warm anomalies are limited to northern Europe, and the largest anomalies $\left(>1.0^{\circ} \mathrm{C}\right)$ are found over Scandinavia.

The similarity between the two warm periods can also be seen in the seasonal evolution of Central England Temperature (CET) and European surface air temperature (see SI, Fig S1). In both periods both indices are anomalously warm from March through to September (and also in November). These results are consistent with the seasonal mean correlations between the AMO and CET reported by KFSO6, and suggest that a warm state of the North Atlantic favours a mild spring (especially April), summer and autumn, in England and across Europe.

The patterns of precipitation anomalies are, not unexpectedly, noisier than those for SAT but there is again a high degree of consistency between the two warm periods, especially in summer (Fig 3). In spring, dry anomalies are found over the UK and France, and wet anomalies over Iberia, but the patterns are quite noisy, especially further east. In summer, however, there is a very clear banded pattern of wet anomalies extending across northern and central Europe (with a small region of dry anomalies along the west coast of Norway) and dry anomalies across southern Europe, reaching from Portugal to Turkey. Anomalies are 5-20\% of the local seasonal mean rainfall (SI). In autumn, dry anomalies (up to $20 \%$ of the seasonal mean value) are found over Scandinavia, and wet anomalies of similar magnitude are found over the UK and southeastern Europe in both periods. Anomalies over Iberia differ in sign between the two periods.

A warm state of the North Atlantic Ocean could cause warm anomalies in SAT over Europe without any significant effects on atmospheric circulation (by advection over land of air warmed by the ocean). However, the coherent and consistent patterns of precipitation anomalies suggest changes in atmospheric circulation, which are confirmed by Fig 4. In spring, there is an anomalous ridge (high SLP) over central Europe, 
sandwiched between two anomalous troughs (low SLP) over the northeast Atlantic Ocean and northeastern Europe. It is likely that this ridge is linked to the low (dry) precipitation anomalies seen over the UK and France in this season (Fig 3). The implied anomalous southerly flow over western Europe may also contribute to the warm SAT anomalies (Fig 2). In summer, the pattern of SLP anomalies over North Africa, the northeast Atlantic and western Europe is again consistent between the two periods. The anomalous trough centred over western Europe is consistent with the band of high (wet) precipitation anomalies that stretches eastward from the UK through central and northern Europe (Fig 3). This pattern of anomalies is very similar to the Summer $\mathrm{NAO}^{6}$. In autumn, a dipolar pattern of SLP anomalies is located over Europe with an anomalous ridge over Scandinavia and northeastern Europe, and an anomalous trough over southern Europe, the Mediterranean Sea and North Africa. This pattern is again consistent with the pattern of precipitation anomalies (dry over Scandinavia and northeastern Europe and wet over central and southern Europe, Fig 3). Note that, in all seasons, the patterns of SLP and precipitation anomalies are very similar when no detrending is used (not shown).

The consistency between the two warm North Atlantic periods in the patterns of anomalies in SAT, precipitation and SLP is strong circumstantial evidence that the North Atlantic Ocean was an important driver of these decadal variations in European climate. This hypothesis is supported by the correlations on decadal timescales between the AMO and indices of seasonal mean SAT, SLP and precipitation variability (see SI, Figs S2-S4 and Table S1). Substantial further evidence for summer in particular is provided by the consistency between the observed pattern of anomalies, and patterns obtained in climate model simulations in which the Atlantic Ocean is unambiguously the driver responsible ${ }^{4,5}$ (Fig 2 of $\mathrm{SHO5}^{4}$; Fig 3 of $\mathrm{KFSO6}^{5}$ ). Indeed, the pattern of anomalies we have shown for the recent warm period is entirely consistent with the prediction provided at the end of SH05, of "increased [relative to 1961-90] summer precipitation and temperatures in western Europe". Put together, the evidence is compelling that the North Atlantic Ocean was indeed the driver of the shift in European summer climate that took place in the 1990s.

The anomalies that KFS06 found for spring and autumn show some differences from those we have identified in the observations. The patterns of SLP anomalies are similar to ours over the North Atlantic (particularly for spring), but they differ over Europe. As expected, these differences in circulation anomalies are associated with different precipitation anomalies: in autumn, for example, KFSO6 show increased precipitation in northern Europe and decreased precipitation in southern Europe, whereas we find approximately the opposite pattern. We hypothesise that these differences are caused by biases in the climate model used by KFS06. Testing this hypothesis with other climate models is an important area for future work. An alternative hypothesis is that other factors, not included in the simulations of KFS06, are important in spring and autumn; however, to account for our results, any such factors must vary in phase with the AMO.

Our results enhance significantly the growing body of evidence ${ }^{1-6,18-21}$ that the AMO is a key driver of decadal variability in the climate of Europe and other regions. They also suggest that the recent pattern of mild, wet, summers in northern Europe and hot, dry summers in Southern Europe (and the related patterns of warm, dry, springs in northwestern Europe, warm dry autumns in Scandinavia, and wet autumns in southeastern Europe) may be expected to continue as long as the current warm phase of the AMO persists. However, it is uncertain how long this will be. This uncertainty reflects gaps in understanding of the factors that drive the AMO.$^{5,16,17}$ The evidence that the AMOC played an important role in the transition to a warm phase during the $1990 \mathrm{~s}^{13}$ suggests that the behaviour of the AMOC is likely to be one important factor for the future of 
the AMO. Some decline in the AMOC, favouring a return to the cool phase of the AMO, seems likely. Such a decline could arise as a response to the observed decline in the winter NAO index ${ }^{24}$, following its peak in the early 1990s, or in response to recent and future surface warming (which acts to inhibit deep water formation in the subpolar North Atlantic). An interesting possibility is that the transition to a cool phase of the AMO or part of such a transition - might occur rapidly, as seems to have occurred during the last transition from a warm to a cool phase ${ }^{25}$. Were this to happen, our results suggest that the consequences would include a rapid change in European climate, albeit one of uncertain magnitude.

\section{Methods Summary}

We used four datasets derived from observations. HadISST ${ }^{26}$ provides monthly mean sea surface temperature (SST) from 1871 to 2010 on a $1^{\circ} \times 1^{\circ}$ grid. HadSLP2r provides a near-real-time update of HadSLP2 $2^{27}$ monthly mean sea level pressure (SLP) from 1851 to 2010 on a $5^{\circ} \times 5^{\circ}$ grid. HadCET $^{28}$ provides monthly mean Central England Temperature (CET) from 1659 to 2010. These three datasets are available from http://www.metoffice.gov.uk/hadobs/. The CRU TS3.1 $1^{29}$ dataset, which provides monthly mean land surface air temperature (SAT) and land precipitation from 1901 to 2009 , on a $0.5^{\circ} \times 0.5^{\circ}$ grid, is produced by Climate Research Unit (CRU) at the University of East Anglia, and is available from the British Atmospheric Data Centre (http://badc.nerc.ac.uk/view/badc.nerc.ac.uk ATOM dataent 1256223773328276.) Seasonal mean values for spring (March-May, MAM), summer (June-August, JJA), and autumn (SeptemberNovember, SON) were constructed for SAT, SLP and precipitation by averaging corresponding monthly mean values. The AMO index (Fig 1a) is defined as the annual mean HadISST sea surface temperature (SST) anomaly averaged over the region $0^{\circ} \mathrm{N}-60^{\circ} \mathrm{N}, 75^{\circ} \mathrm{W}-7.5^{\circ} \mathrm{W}$. The gSSTmA index is defined as the annual mean global mean SST excluding the North Atlantic (gSSTmA; Fig 1a). Low pass filtered versions of these indices were generated using a Chebyshev recursive filter ${ }^{30}$ with a cut-off at 11 years to remove the interannual variability. SAT, SLP and precipitation data were detrended by removing the regression at each grid point to this low-pass filtered gSSTmA index. For each detrended variable or field, means and variances were computed for the North Atlantic warm periods 1931-1960 and 1996-2010 (1996-2009 in the case of SAT and precipitation), and the cool period 1964-1993. Anomalies were calculated as the differences between the means for the relevant warm period and the mean for the cool period. Statistical significance was assessed using a two tailed Student t-test. 


\section{Figure Legends}

Figure 1: The Atlantic Multidecadal Oscillation (AMO). a. AMO index (black) of North Atlantic SST, and gSSTmA index (thin blue) of SST outside the North Atlantic; thick red and blue lines show low pass filtered indices b. AMO index as in a after the low pass filtered gSSTmA index has been subtracted. Thick black horizontal lines indicate the periods used to define the warm and cool phases of the AMO. c \& d. Annual mean SST anomalies for the two warm AMO phases relative to the intervening cool phase, after detrending using the low-pass filtered gSSTmA index. See Methods for details.

Figure 2: Anomalies in Surface Air Temperature (SAT) during the recent warm phases of the AMO, relative to the intervening cool phase. a. b. c. Seasonal mean (MAM, JJA, SON) SAT anomalies $\left({ }^{\circ} \mathrm{C}\right)$ for (1931-60)(1964-93). d. e. f., as in a. b. c., but for (1996-2009)-(1964-93). The seasonal mean data at each grid point were detrended by removing the linear regression to the low-pass filtered gSSTmA index before calculating the anomalies. Only anomalies significant at the $90 \%$ confidence level are plotted.

Figure 3: Anomalies in precipitation during the recent warm phases of the AMO, relative to the intervening cool phase. a.-f As Fig 2 but for seasonal mean precipitation anomalies expressed as a percentage of the climatological (mean) value for 1901-2009; no local significance cut off is applied to precipitation. Boxes indicate regions used to calculate the precipitation indices for JJA and SON that are shown in Fig S3.

Figure 4: Anomalies in sea level pressure (SLP) during the recent warm phases of the AMO, relative to intervening the cool phase. a.-f As Fig 3 but for seasonal mean SLP anomalies (hPa); solid black contours indicate the $90 \%$ confidence level. Boxes indicate regions used to calculate the SLP indices that are shown in Fig S4. 
1. Schlesinger, M. E. \& Ramankutty, N., An oscillation in the global climate system of period 65-70 years. Nature 367,723-726 (1994).

2. Kushnir, Y. Interdecadal variations in North Atlantic sea surface temperature and associated atmospheric conditions. J. Clim. 7, 141-157 (1994).

3. Delworth, T.L. \& Mann, M.E., Observed and simulated multidecadal variability in the Northern Hemisphere, Climate Dynamics, 16, 9, 661-676, DOI: 10.1007/s003820000075 (2000)

4. Sutton, R. T. \& Hodson, D. L. R., Atlantic Ocean forcing of North American and European summer climate. Science 309, 115-118 (2005).

5. Knight, J., Folland, C. K. \& Scaife, A., Climate impacts of the Atlantic Multidecadal Oscillation. Geophys. Res. Lett. 33.L17706, doi:10.1029/2006GL026242 (2006).

6. Folland CK, Knight J, Linderholm HW, Fereday D, Ineson S, Hurrell JW. The Summer North Atlantic oscillation: past, present, and future. J Clim 22:1082-1103. doi:10.1175/2008JCLI2459.1 (2009).

7. Hoerling, M. P. Hurrell, J. W. \& Xu, T. Tropical origins for recent North Atlantic climate change, Science 292, 90-92 (2001).

8. Shindell, D. T. Schmidt, G. A. Miller, R. L. \& Rind, D. Northern Hemisphere winter climate response to greenhouse gas, ozone, solar, and volcanic forcing. J. Geophys. Res. 106, 7193-7210 (2001).

9. Deser, C. Magnusdottir, G. Saravanan, R. \& Phillips, A.S. The effects of North Atlantic SST and sea-ice anomalies on the winter circulation in CCM3. Part II: Direct and indirect components of the response. J. Climate. 17, 877-891 (2004).

10. Scaife, A.A. Knight, J.R. Vallis, G. \& Folland, C. K. A. stratospheric influence on the winter NAO and north Atlantic surface climate. Geophys. Res. Lett. 32,L187152 (2005).

11. Ineson, S. et al. Solar forcing of winter climate variability in the Northern Hemisphere. Nat Geosci. 4, 753-757, doi:10.1038/ngeo1282 (2011).

12. Hegerl, G., Luterbacher, J., González-Rouco, F., Tett, S.F.B., \& Crowley, T.J. Influence of human and natural forcing on European seasonal temperatures. Nat Geosci. doi:10.1038/NGEO1057 (2011).

13. Robson, J. Sutton, R. Lohmann, K. Smith, D. \& Palmer, M. The causes of the rapid warming of the North Atlantic Ocean in the mid 1990s. J. Climate, 25, 4116-4134, (2012).

14. Enfield, D. B. Mestas-Nunez, A. M. \& Trimble, P. J. The Atlantic multidecadal oscillation and its relationship to rainfall and river flows in the continental US. Geophys. Res. Lett. 28, 2077-2080 (2001).

15. Gray, S. T. et al. A tree-ring based reconstruction of the Atlantic Multidecadal Oscillation since 1567 A.D. Geophys. Res. Lett. 31: L12205. doi:10.1029/2004GL019932 (2004).

16. Ottera, O.H., Bentsen, M., Drange,H. \& Suo, L. External forcing as a metronome for Atlantic multidecadal variability. Nature Geosci 3:688-694. doi:10.1038/NGEO955, (2010)

17. Booth, B.B.B., Halloran, P. R., Dunstone, N. J., Andrews, T. \& Bellouin, N. Aerosols implicated as a prime driver of $20^{\text {th }}$ century variability within the North Atlantic. Nature, 484, 228-232 (2012).

18. Folland, C. K., Parker, D. E. \& Palmer, T. N. Sahel rainfall and worldwide sea temperatures 1901-85. Nature 320, 602-607 (1986).

19. Zhang, R. \& Delworth, T. L. Impact of Atlantic multidecadal oscillations on India/Sahel rainfall and Atlantic hurricanes, Geophys. Res. Lett., 33, L17712, doi:10.1029/2006GL026267 (2006).

20. Lu, R., B.-W. Dong, and H Ding, Impact of the Atlantic Multidecadal Oscillation on the Asian summer monsoon. Geophys Res Lett 33: L24701, doi:10.1029/2006GL027655 (2006). 
21. Nigam, S., Guan, B. \& Ruiz-Barradas, A. Key role of the Atlantic Multidecadal Oscillation in 20th century drought and wet periods over the Great Plains. Geophys. Res. Lett. 38, L16713, doi:10.1029/2011GL048650 (2011).

22. Lohmann, K. Drange, H. \& Bentsen, M. Response of the North Atlantic subpolar gyre to persistent North Atlantic oscillation like forcing. Clim. Dyn., 32, 273-285 (2009).

23. Frankignoul, Claude, Nadine Chouaib, Zhengyu Liu, Estimating the Observed Atmospheric Response to SST Anomalies: Maximum Covariance Analysis, Generalized Equilibrium Feedback Assessment, and Maximum Response Estimation. J. Climate, 24, 2523-2539. Doi:10.1175/2010JCLI3696.1 (2011)

24. Eden, C., \& Jung, T., North Atlantic Interdecadal Variability: Oceanic Response to the North Atlantic Oscillation (1865-1997), J. Climate, 14, 676-690, (2001)

25. David W. J. Thompson, John M. Wallace, John J. Kennedy \& Phil D. Jones, An abrupt drop in Northern Hemisphere sea surface temperature around 1970, Nature, 467, 444-447 (2010), doi:10.1038/nature09394

26. Rayner, N. A., Parker, D. E., Horton, E. B., Folland, C. K., Alexander, L. V., Rowell, D. P., Kent, E. C., \& Kaplan, A. Global analyses of sea surface temperature, sea ice, and night marine air temperature since the late nineteenth century J. Geophys. Res. 108, D14,4407 doi:10.1029/2002JD002670 (2003).

27. Allan, R. \& Ansell, T. J. A new globally complete monthly historical mean sea level pressure dataset (HadSLP2): 1850-2004. J. Clim. 19, 5816-5842 (2006).

28. Parker, D.E., Legg, T.P., \& Folland, C. K. A new daily Central England Temperature Series, 1772-1991. Int. J. Clim., 12, 317-342 (1992).

29. University of East Anglia Climatic Research Unit (CRU). [Phil Jones, lan Harris]. CRU Time Series (TS) high resolution gridded datasets. NCAS British Atmospheric Data Centre, 2008, Date of citation. Available from http://badc.nerc.ac.uk/view/badc.nerc.ac.uk ATOM dataent 1256223773328276.

30. Cappellini, V., 1978: Digital Filters and Their Applications. Academic Press, 393 pp.

Correspondence and requests for materials should be addressed to Rowan Sutton: r.sutton@reading.ac.uk

\section{Acknowledgments}

This research was supported by the UK National Centre for Atmospheric Science, funded by the Natural Environment Research Council. RS and BD would like to thank Dan Hodson for useful discussions about this work.

Author contributions The original idea for the study came from RS, who also wrote most of the paper. BD carried out all the analyses and contributed to the writing. RS and BD worked together on the interpretation. 


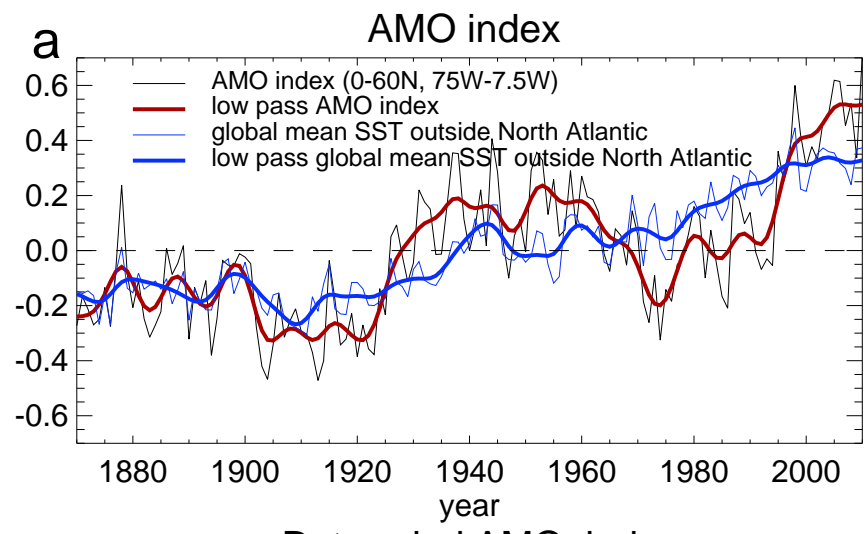

$\mathrm{b}$

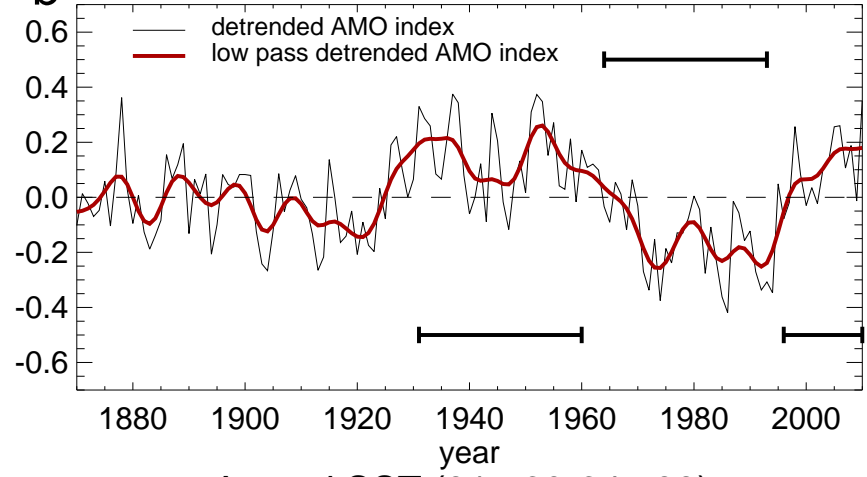

C

Annual SST (31to60-64to93)

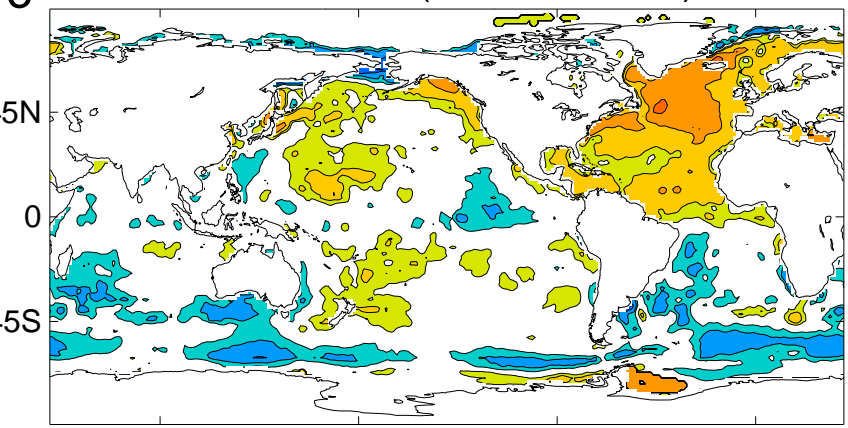

$90 \mathrm{E}$

180

$90 \mathrm{~W}$

$\begin{array}{llllll}-1.6 & -0.8 & -0.2 & 0.1 & 0.4 & 1.2\end{array}$

d

Annual SST (96to 10-64to93)



$90 \mathrm{E}$

180

$90 \mathrm{~W}$ 
